\title{
Non-invasive ventilation for acute hypoxemic respiratory failure: intubation rate and risk factors
}

\author{
Arnaud W Thille ${ }^{1,2,3^{*}}$, Damien Contou ${ }^{1,3}$, Chiara Fragnoli ${ }^{1}$, Ana Córdoba-Izquierdo ${ }^{1}$, Florence Boissier ${ }^{1}$ \\ and Christian Brun-Buisson ${ }^{1,3}$
}

\begin{abstract}
Introduction: We assessed rates and predictive factors of non-invasive ventilation (NIV) failure in patients admitted to the intensive care unit (ICU) for non-hypercapnic acute hypoxemic respiratory failure (AHRF).

Methods: This is an observational cohort study using data prospectively collected over a three-year period in a medical ICU of a university hospital.

Results: Among 113 patients receiving NIV for AHRF, 82 had acute respiratory distress syndrome (ARDS) and 31 had non-ARDS. Intubation rates significantly differed between ARDS and non-ARDS patients (61\% versus 35\%, $P=0.015$ ) and according to clinical severity of ARDS: $31 \%$ in mild, $62 \%$ in moderate, and $84 \%$ in severe ARDS $(P=0.0016)$. In-ICU mortality rates were $13 \%$ in non-ARDS, and, respectively, $19 \%, 32 \%$ and $32 \%$ in mild, moderate and severe ARDS $(P=0.22)$. Among patients with moderate ARDS, NIV failure was lower among those having a $\mathrm{PaO}_{2} / \mathrm{FiO}_{2}>150 \mathrm{mmHg}(45 \%$ vs. $74 \%, \mathrm{p}=0.04)$. NIV failure was associated with active cancer, shock, moderate/ severe ARDS, lower Glasgow coma score and lower positive end-expiratory pressure level at NIV initiation. Among intubated patients, ICU mortality rate was $46 \%$ overall and did not differ according to the time to intubation.

Conclusions: With intubation rates below 35\% in non-ARDS and mild ARDS, NIV stands as the first-line approach; NIV may be attempted in ARDS patients with a $\mathrm{PaO}_{2} / \mathrm{FiO}_{2}>150$. By contrast, $84 \%$ of severe ARDS required intubation and NIV did not appear beneficial in this subset of patients. However, the time to intubation had no influence on mortality.
\end{abstract}

\section{Introduction}

It is now well-demonstrated that non-invasive ventilation (NIV) can reduce intubation and mortality rates in patients with severe acute exacerbation of chronic obstructive pulmonary disease [1-3] or cardiogenic pulmonary edema [4]. By contrast, the beneficial effects of NIV remain unclear in patients with de novo acute hypoxemic respiratory failure (AHRF), that is, non-hypercapnic patients having acute respiratory failure in the absence of a cardiac origin or underlying chronic pulmonary disease. NIV is more likely to fail in hypoxemic patients [5], and NIV failure could be associated with increased mortality [6]. In unselected patients admitted to ICUs for AHRF, the rate of intubation is

\footnotetext{
* Correspondence: aw.thille@gmail.com

${ }^{1}$ Medical Intensive Care Unit, AP-HP, Henri Mondor University Hospital,

Créteil, France

${ }^{2}$ Réanimation Médicale, CHU de Poitiers, 2 rue de la Milétrie, 86021, Poitiers, France

Full list of author information is available at the end of the article
}

particularly high, reaching 60\% [6,7], and their in-ICU mortality after intubation may exceed 60\% [6-8]. Thus, NIV may improve outcome of patients who succeed in NIV by avoiding intubation, but may worsen outcome by delaying intubation in those having failed NIV.

Despite these concerns, surveys show that NIV is increasingly used in patients having AHRF and is initiated as first-line ventilatory support in $20 \%$ to $30 \%$ of such patients [5,7]. NIV has even been used as the first-line ventilatory support in patients having clinical criteria for acute respiratory syndrome (ARDS) $[9,10]$ with a success rate of more than $50 \%$, especially in patients with prompt improvement of oxygenation [9]. The increasing popularity of NIV in AHRF patients is supported by some studies showing that NIV markedly reduced intubation and mortality rates in immunosuppressed patients $[11,12]$ or in selected surgical patients with AHRF $[13,14]$.

\section{Biomed Central}

(c) 2013 Thille et al.; licensee BioMed Central Ltd. This is an open access article distributed under the terms of the Creative Commons Attribution License (http://creativecommons.org/licenses/by/2.0), which permits unrestricted use, distribution, and reproduction in any medium, provided the original work is properly cited. 
However, few randomized controlled studies have been conducted in non-immunosuppressed patients with AHRF [15-18], and some of these included hypercapnic patients [15,16]. To date, only two randomized controlled studies have evaluated NIV in non-hypercapnic patients with AHRF $[17,18]$, with one suggesting that NIV may reduce intubation rate and even mortality [18] and the other reporting no beneficial effects of continuous positive-end expiratory pressure without ventilatory assistance [17].

The aims of our study were to assess the rate of NIV failure in patients admitted for AHRF according to the presence and clinical severity of ARDS as recently defined [19], and to identify early predictors of NIV failure.

\section{Material and methods}

This observational cohort study was conducted in our 24bed medical ICU at Henri Mondor University Hospital in Créteil, France. The Institutional Review Board of the French Society for Respiratory Medicine approved this non-interventional study and waived the need for informed consent.

\section{Patients}

All consecutive patients admitted during a three-year period (June 2008 to June 2011) and who received NIV as initial ventilatory support for AHRF were included. AHRF was defined as recent dyspnea with a respiratory rate $>25$ breaths/minute and/or sternocleidomastoid muscle activation with pulmonary infiltrates on chest X-ray, and a $\mathrm{PaCO}_{2}$ below or equal to $45 \mathrm{mmHg}$. We excluded patients who were intubated before ICU admission or intubated upon ICU admission without prior NIV, and patients for whom NIV was used with a "do not intubate" order. However, the outcome for those who were directly intubated for acute respiratory failure without prior NIV, and who met clinical criteria for moderate or severe ARDS was also collected. The study was conducted after the implementation of a nurse-driven NIV protocol which included prospective daily collection of clinical data and ventilatory parameters on a specific NIV monitoring form. When the NIV form was unavailable or incomplete, data were retrieved from the patient's records.

\section{Non-invasive ventilation protocol and definitions}

All stages of the protocol had been developed within a multidisciplinary working group including ICU physicians, nurses and respiratory therapists. The protocol aimed at empowering nurses to adjust the ventilatory settings and to improve the patient's tolerance to NIV following a simple decision algorithm. A daily NIV prescription by the physician indicated the duration of NIV sessions and targeted expiratory tidal volume (around 6 to $8 \mathrm{ml} / \mathrm{kg})$ and oxygen saturation $\left(\mathrm{SpO}_{2}\right)(\geq 94 \%)$.
Pressure-support (PS) ventilation was started using a pressure-support level of $8 \mathrm{cmH}_{2} \mathrm{O}$, a positive endexpiratory pressure (PEEP) level of $5 \mathrm{cmH}_{2} \mathrm{O}$, an inspiratory trigger of $3 \mathrm{~L} /$ minute, and a maximal inspiratory time of one second. The nurses then adjusted the ventilatory parameters, including pressure-support level and $\mathrm{FiO}_{2}$ (fraction of inspired oxygen), according to the protocol. Pressure-support level was gradually increased by $2 \mathrm{cmH}_{2} \mathrm{O}$ steps to reach the target expiratory tidal volume and PEEP level was then adjusted as prescribed. $\mathrm{FiO}_{2}$ was gradually adjusted by $5 \%$ steps to reach the targeted $\mathrm{SpO}_{2}$. Non-invasive ventilation was applied intermittently for periods of at least two hours, with a minimal duration of six hours per day and was maintained until signs of respiratory distress improved. An algorithm was used by nurses in case of leaks, which involved first repositioning of the mask; second, reducing the PEEP level at $2 \mathrm{cmH}_{2} \mathrm{O}$; third, reducing the pressure-support level by steps of $2 \mathrm{cmH}_{2} \mathrm{O}$ until the minimal expiratory volume was reached; and fourth, changing the mask interface.

A mobile cart containing all types and sizes of interfaces was available at the bedside during initiation of NIV. NIV was performed via a non-vented full-face mask (FreeMotion ${ }^{\mathrm{Tm}}$ RT041, Fisher \& Paykel, Auckland, New Zealand or Ultra Mirage ${ }^{\mathrm{m} w}$, Resmed, CA, USA), with an ICU ventilator using a dedicated NIV mode (Evita XL, Dräger, Lübeck, Germany, or Engström Carestation, GE Healthcare, Fairfield, CT, USA), equipped with a heated humidifier (MR850, Fisher \& Paykel).

The following criteria were used for endotracheal intubation: loss of consciousness or psychomotor agitation hindering nursing care and requiring sedation; persistent hypotension (defined by systolic arterial blood pressure below $90 \mathrm{mmHg}$ or mean arterial blood pressure below $65 \mathrm{mmHg}$ ) despite fluid resuscitation, or need for vasopressors; or two of the following criteria: frank worsening of respiratory distress under NIV, respiratory rate above 40 breaths per minute, $\mathrm{SpO}_{2}$ remaining below $90 \%$ despite $\mathrm{FiO}_{2} 100 \%$, dependence to NIV for more than 12 hours, or $\mathrm{pH}<7.35$. NIV failure was defined by the need for endotracheal intubation.

\section{Data collection}

From the NIV monitoring forms, we analyzed the number and duration of NIV sessions, ventilator settings (pressure support level, positive end-expiratory pressure, $\left.\mathrm{FiO}_{2}\right)$, ventilatory parameters $\left(\mathrm{SpO}_{2}\right.$, respiratory rate, expiratory tidal volume), hemodynamic parameters (heart rate, blood pressure and level of consciousness assessed using the Richmond Agitation-Sedation Scale (RASS) [20], with altered consciousness defined as a RASS $<0$. NIV tolerance and number of leaks were recorded on a 4-point scale, then dichotomized into "acceptable" 
(scored 2 to 3 ) or "poor" (scored 0 to 1 ) tolerance, and "minor" (scored 0 to 1 ) or "major" (scored 2 to 3 ) leaks, respectively. Blood gases were routinely measured one hour after initiation of NIV. Clinical data (respiratory rate, $\mathrm{SpO}_{2}$, blood pressure, heart rate, Glasgow coma score) and blood gases at admission before NIV initiation were retrospectively collected from the medical chart. We also recorded the occurrence of shock at admission or at initiation of NIV (defined by hypoperfusion signs and administration of at least $30 \mathrm{ml} / \mathrm{kg}$ fluids, dobutamine or vasopressors).

Patients were stratified according to the presence of clinical criteria for ARDS. The severity of ARDS was stratified using the recent Berlin definition [19], according to the value of oxygenation recorded within the first hour after NIV initiation, and classified as mild (201 $\leq \mathrm{PaO}_{2} / \mathrm{FiO}_{2}$ (partial pressure of oxygen/fraction of inspired oxygen $) \leq 300 \mathrm{mmHg})$, moderate $\left(101 \leq \mathrm{PaO}_{2} /\right.$ $\left.\mathrm{FiO}_{2} \leq 200 \mathrm{mmHg}\right)$ or severe $\left(\mathrm{PaO}_{2} / \mathrm{FiO}_{2} \leq 100 \mathrm{mmHg}\right)$.

\section{Statistical analysis}

Dichotomous variables are reported as number (percentage), and were compared using the chi-square or Fisher's exact tests. Continuous variables are expressed as mean ( \pm standard deviation) or as median and interquartile range (IQR, $\left(25^{\text {th }}\right.$ to $75^{\text {th }}$ percentiles)) after testing their normal distribution using the Shapiro-Wilk test. Groups were compared using the unpaired Student's $t$-test or Wilcoxon rank-sum and Kruskall-Wallis tests, when appropriate. Odds ratios (OR) with 95\% confidence intervals (CI) were used to describe differences between subgroups for NIV failure or death.

Survival without intubation was tested using KaplanMeier estimates and compared with the log-rank test. To evaluate independent factors associated with NIV failure, variables with a univariate $P$-value $<0.10$ were entered in a Cox proportional hazards model with time to intubation as the dependent variable, censoring data at ICU discharge. Among related variables, the most significant or clinically relevant was entered into the model in order to minimize the effect of colinearity. Because it was measured at 24 hours after admission, the general severity score SAPS 2 was not included in this analysis. Variables included in the model are reported with their corresponding hazard ratio (HR) and 95\% CI. We considered two-tailed $P$-values $<0.05$ as significant. Statistical analyses were performed using the statistical software package STATA version 10.1 (Stata Corp., TX, USA).

\section{Results}

\section{Patients}

Among 430 patients who received NIV during the study period, 188 had non-hypercapnic acute respiratory failure. After excluding patients with cardiogenic pulmonary edema and those without pulmonary infiltrates, 113 had de novo acute hypoxemic respiratory failure (Figure 1). Eighty-two patients had clinical criteria for ARDS at the time of NIV initiation, including 16 with mild (20\%), 47 with moderate (57\%) and 19 (23\%) with severe ARDS. ARDS was due to bacterial pneumonia $(n=21)$, viral pneumonia $(n=7)$, pneumocystis jirovecii $(n=4)$, pneumonia without microbiological documentation $(n=24)$, aspiration $(n=5)$, alveolar hemorrhage $(n=6)$, drug induced pneumonia $(n=5)$, extra-pulmonary sepsis $(n=8)$, transfusion acute lung injury $(\mathrm{n}=1)$, and fat embolism $(\mathrm{n}=1)$. The 31 remaining patients without clinical criteria for ARDS (non-ARDS) had pneumonia $(\mathrm{n}=17)$, atelectasis $(n=5)$, aspiration $(n=4)$, intra-alveolar hemorrhage $(n=2)$, pleural effusion $(n=2)$ or extra-pulmonary sepsis $(\mathrm{n}=1)$. Overall, 50 patients $(44 \%)$ were immunocompromised (Table 1), because of hematologic malignancy $(n=22)$, organ transplant $(n=10)$, HIV infection $(n=6)$, vasculitidis or steroid therapy $(n=4)$ or active/metastatic solid cancer $(\mathrm{n}=8)$.

\section{Rates of NIV failure and in-ICU mortality}

The rate of intubation was 61\% (50/82) in ARDS and $35 \%(11 / 31)$ in non-ARDS patients $(P=0.015)$. This rate did not differ between patients without ARDS or those with mild ARDS $(P=0.71)$, but increased with increasing clinical severity of ARDS from 31\% (5/16) in mild, 62\% $(29 / 47)$ in moderate, to $84 \%(16 / 19)$ in severe ARDS $(P=0.0016)$ (Figure 2). Patients with moderate or severe ARDS were twice as likely to fail $\operatorname{NIV}(45 / 66,68 \%)$ than

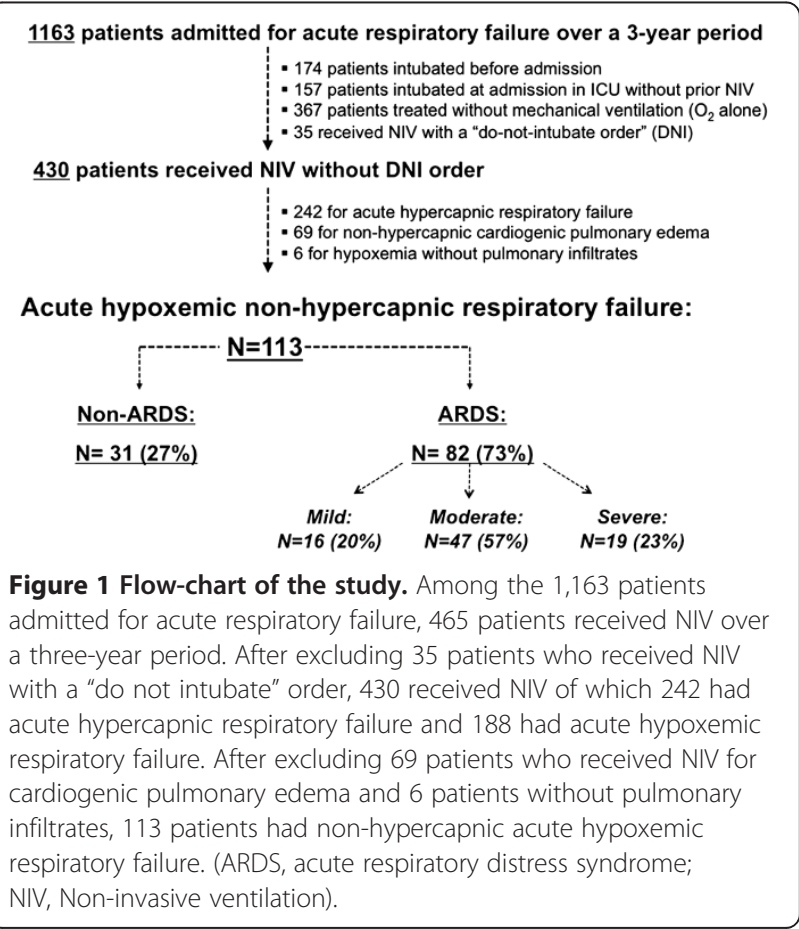


Table 1 Characteristics and outcomes of the patients receiving NIV for non-hypercapnic AHRF

\begin{tabular}{llll}
\hline & $\begin{array}{l}\text { No ARDS or mild } \\
\text { ARDS }(\mathbf{n}=\mathbf{4 7})\end{array}$ & $\begin{array}{l}\text { Moderate or severe } \\
\text { ARDS }(\mathbf{n}=66)\end{array}$ & $\mathbf{P}$ \\
\hline Age, mean, years & $60( \pm 15)$ & $61( \pm 17)$ & 0.72 \\
Male sex, $\mathrm{n}(\%)$ & $30(64 \%)$ & $45(68 \%)$ & 0.62 \\
SAPS II, points* & $33(23$ to 39$)$ & $41(30$ to 51$)$ & 0.0014 \\
$\begin{array}{l}\text { Immunosuppression } \\
\text { or cancer, } \mathrm{n}(\%)\end{array}$ & $17(36 \%)$ & $33(50 \%)$ & 0.15 \\
\end{tabular}

\section{Characteristics at} admission before

NIV

\begin{tabular}{|c|c|c|c|}
\hline Sepsis, n (\%) & $27(73 \%)$ & $53(70 \%)$ & 0.72 \\
\hline $\begin{array}{l}\text { Systolic arterial } \\
\text { pressure, } \mathrm{mmHg}\end{array}$ & $131( \pm 25)$ & $127( \pm 27)$ & 0.43 \\
\hline $\begin{array}{l}\text { Heart rate, beats/ } \\
\text { minute }\end{array}$ & $114( \pm 25)$ & $110( \pm 26)$ & 0.43 \\
\hline $\begin{array}{l}\text { Respiratory rate, } \\
\text { cycles/minute }\end{array}$ & $33( \pm 7)$ & $33( \pm 7)$ & 0.78 \\
\hline $\begin{array}{l}\text { Glasgow coma scale, } \\
\text { points** }\end{array}$ & 15 (15 to 15$)$ & 15 (15 to 15$)$ & 0.75 \\
\hline $\mathrm{pH}$, units* & 7.4 (7.43 to 7.49$)$ & 7.45 (7.40 to 7.48$)$ & 0.24 \\
\hline $\mathrm{PaCO}_{2}, \mathrm{~mm} \mathrm{Hg}$ & $34.6( \pm 6.3)$ & $35.4( \pm 5.0)$ & 0.43 \\
\hline $\mathrm{PaO}_{2}, \mathrm{~mm} \mathrm{Hg}$ & $77( \pm 41)$ & $85( \pm 54)$ & 0.43 \\
\hline Bicarbonates, mmol/L & $25.0( \pm 4.8)$ & $24.5( \pm 5.0)$ & 0.58 \\
\hline Lactates, mmol/L* & 1.4 (1.0 to 2.0$)$ & 1.9 (1.1 to 2.6$)$ & 0.054 \\
\hline \multicolumn{4}{|l|}{$\begin{array}{l}\text { At } 1 \mathrm{~h} \text { of NIV } \\
\text { initiation }\end{array}$} \\
\hline $\mathrm{pH}^{*}$ & 7.46 (7.39 to 7.49$)$ & 7.42 (7.38 to 7.46$)$ & 0.03 \\
\hline $\mathrm{PCO}_{2}, \mathrm{~mm} \mathrm{Hg}$ & $36.1( \pm 6.6)$ & $37.8( \pm 7.4)$ & 0.21 \\
\hline $\mathrm{PaO}_{2} / \mathrm{FiO}_{2}, \mathrm{~mm} \mathrm{Hg}^{*}$ & 266 (219 to 330) & 124 (94 to 164$)$ & $<0.000$ \\
\hline PEEP level, $\mathrm{cm} \mathrm{H}_{2} \mathrm{O}$ & $4.7( \pm 1.1)$ & $4.5( \pm 1.1)$ & 0.46 \\
\hline PS level, $\mathrm{cm} \mathrm{H}_{2} \mathrm{O}^{*}$ & 8.0 (6.5 to 10$)$ & 8.0 (6 to 8$)$ & 0.46 \\
\hline Tidal volume, ml & $579( \pm 174)$ & $613( \pm 173)$ & 0.37 \\
\hline $\begin{array}{l}\text { Respiratory rate, } \\
\text { breaths/minute* }\end{array}$ & 34.5 (25 to 40$)$ & 32 (26 to 37.5$)$ & 0.45 \\
\hline \multicolumn{4}{|l|}{ Outcome } \\
\hline $\begin{array}{l}\text { Duration of NIV Day 1, } \\
\text { hours* }\end{array}$ & $6.8[4.0$ to 10.0$]$ & 5.2 [2.0 to 10.0$]$ & 0.19 \\
\hline $\begin{array}{l}\text { Total duration of } \\
\text { NIV, days* }\end{array}$ & $2.0[1.0$ to 3.0$]$ & $1.0[1.0$ to 2.5$]$ & 0.17 \\
\hline $\begin{array}{l}\text { Rate of NIV Failure, } \\
\mathrm{n}(\%)\end{array}$ & $16(34 \%)$ & $45(68 \%)$ & 0.0003 \\
\hline $\begin{array}{l}\text { Length of stay in } \\
\text { ICU, days* }\end{array}$ & $8.0[5.0$ to 15.0$]$ & $10.0[6.0$ to 14.0$]$ & 0.53 \\
\hline ICU mortality, n (\%) & $7(15 \%)$ & $21(32 \%)$ & 0.04 \\
\hline
\end{tabular}

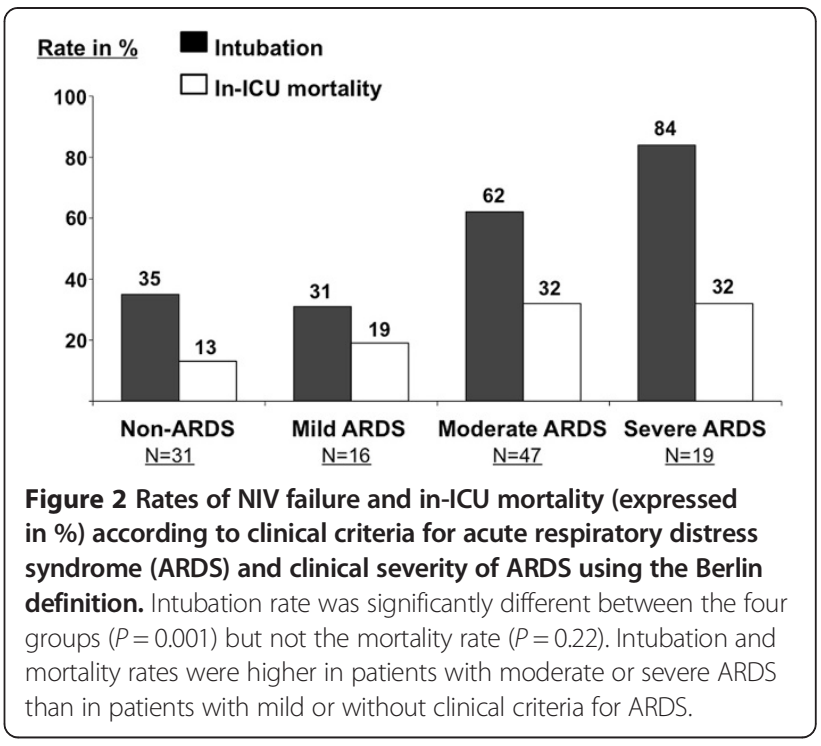

those with no ARDS or with mild ARDS (16/47, 34\%); $(\mathrm{OR}=4.15,95 \% \mathrm{CI}: 1.78$ to $9.70 ; P=0.0004)$ Survival analysis showed that intubation rates differed markedly $(P<0.00001$, Log-rank test) between patients with no or mild ARDS and those with moderate or severe ARDS (Figure 3).

Overall in-ICU mortality rate was $25 \%$ (28/113), and tended to be higher in patients with ARDS (24/82, 29\%) than others $(4 / 31,13 \%, P=0.07)$ (Figure 2). The mortality rate of patients with moderate or severe ARDS was also twice as high $(21 / 66 ; 32 \%)$ as those with no or mild ARDS $(7 / 47 ; 15 \%)(\mathrm{OR}=2.7 ; 95 \% \mathrm{CI}: 1.003$ to $7.09 ; P=0.041)$.

Among intubated patients, the overall in-ICU mortality rate was $46 \%(28 / 61)$. Thirty-three patients $(54 \%)$

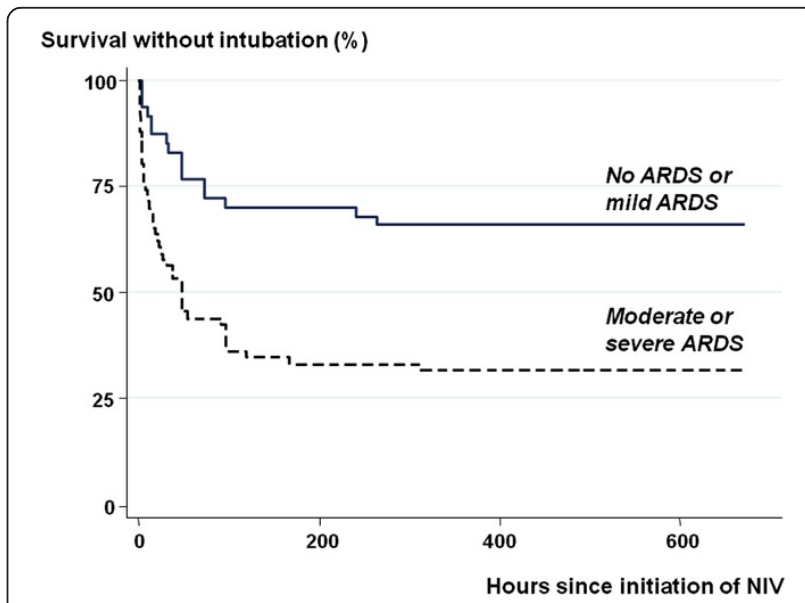

Figure 3 Kaplan-Meier estimate of survival without intubation according to presence of ARDS and its severity at presentation, stratified as no ARDS or mild ARDS (solid line) or moderate or severe ARDS (dashed line). The difference between the two groups was highly significant $(P<0.0001$, log-rank test). (ARDS, acute respiratory distress syndrome). 
were intubated within the first 24 hours while the 28 patients remaining (46\%) were intubated beyond 24 hours. The delay between NIV initiation and intubation had no influence on outcome with a similar time to intubation in survivors and non-survivors (Figure 4). Among patients with moderate or severe ARDS, in-ICU mortality was similar in patients who were intubated after failure of NIV as compared to patients who were directly intubated without prior NIV (Figure 5).

\section{Factors associated with NIV failure}

Prospective data from NIV monitoring forms were available for $81 \%$ (91/113) of patients. Patients who were not intubated received NIV during a longer duration than those who were intubated $(3.3 \pm 2.8$ days versus $2.0 \pm$ 2.0 days, $P=0.006$ ). Patients who failed NIV had lower PEEP levels and poorer tolerance to NIV than patients who succeeded NIV. Patients who failed NIV had more often active cancer, shock on admission and moderate/ severe ARDS. They also had a higher SAPS II score, a lower Glasgow coma score, and a lower $\mathrm{PaO}_{2} / \mathrm{FiO}_{2}$ ratio (Table 2). Among patients with moderate ARDS, those with a $\mathrm{PaO}_{2} / \mathrm{FiO}_{2}$ ratio $<150$ were at significantly higher risk of intubation: $20 / 27(74 \%)$ vs. $9 / 20(45 \%) ; \mathrm{HR}=2.3$ (95\% CI, 1.04 to 5.06 ); $P=0.04$. The rate of microbiological documentation was similar in patients who succeeded NIV as compared to those who failed NIV: $44 \%$ $(23 / 52)$ in the success group versus $49 \%(30 / 61)$ in the failure group $(P=0.70)$.

Cox regression analysis showed that the risk of intubation was significantly associated with active cancer, a lower Glasgow coma score, shock, moderate/severe ARDS and a lower PEEP level (Table 2).

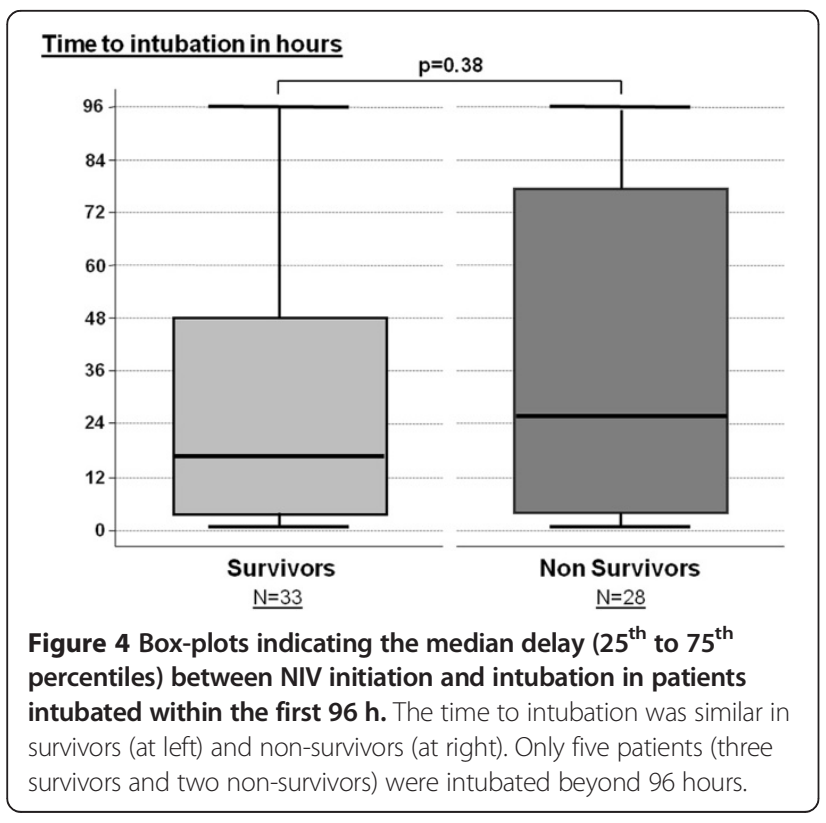

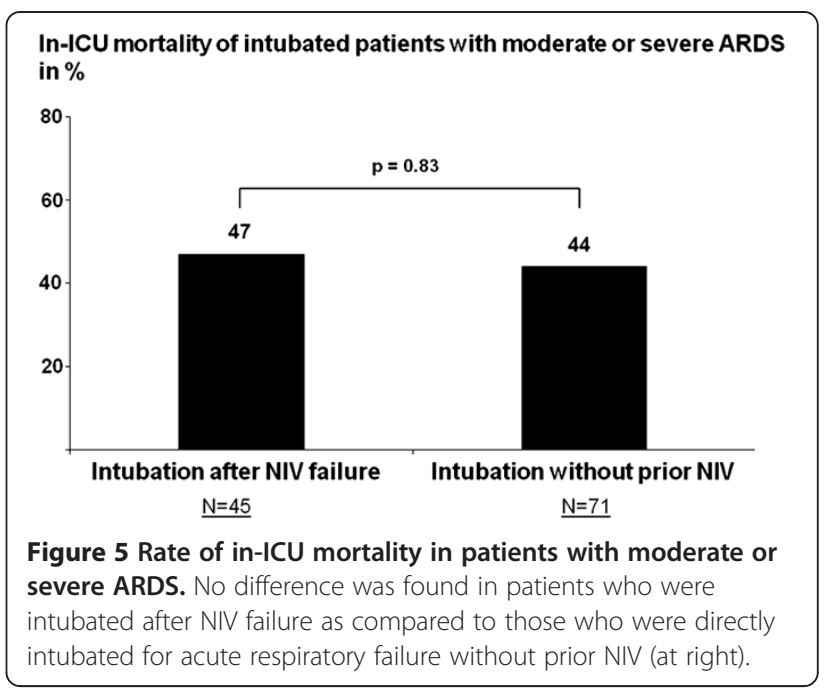

\section{Discussion}

In our study, the intubation rate was higher in ARDS patients $(61 \%)$ than in non-ARDS patients (35\%). However, the $31 \%$ intubation rate in mild ARDS was close to that of non-ARDS, whereas it significantly increased up to $62 \%$ in moderate ARDS and to $84 \%$ in severe ARDS. After adjustment, underlying active cancer, moderate or severe ARDS, shock, lower Glasgow Coma Score (GCS) and lower PEEP level at NIV initiation were predictors of intubation. After NIV initiation, the time to intubation in patients who failed NIV did not influence outcome.

\section{NIV failure rate in patients with acute hypoxemic respiratory failure}

In patients receiving NIV for AHRF, we found an overall rate of intubation of $54 \%$, which is substantially higher than the 25 to $35 \%$ rate reported in randomized controlled trials evaluating NIV in AHRF $[17,18]$. However, in these two studies nearly 20 to $30 \%$ of the patients received NIV for cardiogenic pulmonary edema. Moreover, patients enrolled in such randomized studies are selected and, consistent with our results, intubation rates up to $60 \%$ have been reported in a series of unselected patients with AHRF of non-cardiac origin [6-8].

In their analysis of 147 ARDS patients receiving NIV as first-line therapy, Antonelli et al. [9] reported an intubation rate of only $46 \%$. In this study, a high SAPS 2 (> 34) and low $\mathrm{PaO}_{2} / \mathrm{FiO}_{2}$ ratio $(\leq 175 \mathrm{mmHg}$ ) after NIV initiation were the two risk factors of NIV failure, with an intubation rate of $78 \%(25 / 32)$ when both risk factors were present [9]. Although our overall intubation rate was higher, the intubation rate of patients presenting with the combination of these two criteria was strictly similar (79\%, 27/34) and their mortality rate was likewise similar. However, using the SAPS 2 is clinically impractical since this score is computed only after 24 hours of admission, 
Table 2 Predictors of endotracheal intubation in patients receiving NIV for non-hypercapnic AHRF

\begin{tabular}{|c|c|c|c|c|}
\hline & NIV Success $N=52$ & NIV Failure $\mathrm{N}=61$ & $\begin{array}{l}\text { Univariate HR }[95 \% \mathrm{Cl}] ; \\
P \text {-value }\end{array}$ & $\begin{array}{l}\text { Cox regression aHR }[95 \% \mathrm{Cl}] \\
P \text {-value }\end{array}$ \\
\hline Age, years & $58.0( \pm 17.1)$ & $62.6( \pm 14.4)$ & $1.47[0.99$ to 1.02$] ; P=0.142$ & - \\
\hline Male sex, n (\%) & $36(69 \%)$ & $39(64 \%)$ & $0.85[0.51$ to 1.44$] ; P=0.551$ & - \\
\hline SAPS $\|$ & $31.4( \pm 10.9)$ & $46.3( \pm 18.2)$ & 1.05 [1.03 to 1.06$] ; P<0.001$ & Not included \\
\hline Immunosuppression/cancer, n (\%) & $20(38 \%)$ & $30(49 \%)$ & $1.30[0.79$ to 2.16$] ; P=0.169$ & - \\
\hline Cancer, n (\%) & $0(0 \%)$ & $8(13 \%)$ & $4.36[2.01$ to 9.44$] ; P<0.001$ & $2.74[1.22$ to 6.15$] ; P=0.014$ \\
\hline \multicolumn{5}{|l|}{ At Admission before VNI } \\
\hline Sepsis, n (\%) & $37(71 \%)$ & $43(70 \%)$ & $0.97[0.56$ to 1.68$] ; P=0.913$ & - \\
\hline Glasgow coma score & $14.9( \pm 0.5)$ & $14.6( \pm 1.2)$ & $0.84[0.69$ to 1.03$] ; P=0.098$ & 0.77 [0.63 to 0.96$] ; P=0.018$ \\
\hline Respiratory Rate, breaths/minute & $32.7( \pm 7.0)$ & $33.3( \pm 6.6)$ & $1.01[0.97$ to 1.05$] ; P=0.517$ & - \\
\hline $\mathrm{pH}$ & $7.44( \pm 0.06)$ & $7.44( \pm 0.08)$ & $2.16[0.05$ to 89.3$] ; P=0.685$ & - \\
\hline $\mathrm{PaO}_{2}, \mathrm{~mm} \mathrm{Hg}$ & $78.7( \pm 43.0)$ & $84.1( \pm 53.2)$ & $1.00[0.99$ to 1.01$] ; P=0.442$ & - \\
\hline $\mathrm{PaCO}_{2}, \mathrm{~mm} \mathrm{Hg}$ & $34.8( \pm 5.6)$ & $35.3( \pm 6.0)$ & $1.01[0.97$ to 1.06$] ; P=0.669$ & - \\
\hline Bicarbonates, $\mathrm{mmol} / \mathrm{L}$ & $24.4( \pm 4.8)$ & $25.5( \pm 5.0)$ & $1.01[0.96$ to 1.06$] ; P=0.547$ & - \\
\hline Lactates, mmol/L & $2.0( \pm 1.8)$ & $1.9( \pm 1.2)$ & $1.00[0.85$ to 1.18$] ; P=0.940$ & - \\
\hline Heart rate, beats/minute & $114( \pm 27)$ & $110( \pm 25)$ & $0.99[0.98$ to 1.01$] ; P=0.467$ & - \\
\hline Shock, n (\%) & $4(8 \%)$ & $14(23 \%)$ & $2.08[1.14$ to 3.79$] ; P=0.017$ & $1.89[1.01$ to 3.53$] ; P=0.047$ \\
\hline Systolic arterial pressure, $\mathrm{mmHg}$ & $134( \pm 27)$ & $124( \pm 24)$ & $0.99[0.98$ to 1.00$] ; P=0.055$ & Not included \\
\hline \multicolumn{5}{|l|}{ At NIV initiation } \\
\hline Altered consciousness, n (\%) & $3(6 \%)$ & $8(13 \%)$ & $1.71[0.81$ to 3.59$] ; P=0.158$ & - \\
\hline $\mathrm{pH}$ & $7.43( \pm 0.06)$ & $7.41( \pm 0.10)$ & $0.12[0.00$ to 4.31$] ; P=0.244$ & - \\
\hline $\mathrm{PCO}_{2}, \mathrm{~mm} \mathrm{Hg}$ & $36.6( \pm 6.7)$ & $37.5( \pm 7.5)$ & $1.02[0.98$ to 1.05$] ; P=0.327$ & - \\
\hline $\mathrm{PaO}_{2} / \mathrm{FiO}_{2}, \mathrm{~mm} \mathrm{Hg}$ & $211( \pm 86)$ & $163( \pm 92)$ & 0.99 [0.99 to 0.99$] ; P=0.003$ & Not included \\
\hline Moderate or severe ARDS, n (\%) & $21(40 \%)$ & $45(74 \%)$ & $2.79[1.57$ to 4.95$] ; P<0.001$ & $2.57[1.33$ to 4.75$] ; P=0.003$ \\
\hline $\mathrm{PaO}_{2} / \mathrm{FiO}_{2}<150 \mathrm{~mm} \mathrm{Hg}, \mathrm{n}(\%)$ & $12(23 \%)$ & 37 (61\%) & $2.97[1.77$ to 4.99$] ; P<0.001$ & Not included \\
\hline PEEP level, $\mathrm{cm} \mathrm{H}_{2} \mathrm{O}$ & $4.8( \pm 1.0)$ & $4.4( \pm 1.3)$ & $0.77[0.62$ to 0.94$] ; P=0.011$ & 0.71 [0.57 to 0.88 ] 0.002 \\
\hline 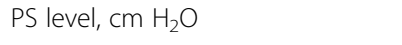 & $8.1( \pm 2.2)$ & $8.0( \pm 1.9)$ & $0.98[0.86$ to 1.13$] ; P=0.915$ & - \\
\hline Tidal volume, $\mathrm{ml}$ & $576( \pm 144)$ & $619( \pm 196)$ & $1.00[0.99$ to 1.00$] ; P=0.157$ & - \\
\hline Respiratory rate, breaths/minute & $32.7( \pm 12.9)$ & $33.9( \pm 9.0)$ & $1.01[0.98$ to 1.03$] ; P=0.601$ & - \\
\hline Important leaks, n (\%) & $2 / 43(5 \%)$ & $3 / 48(6 \%)$ & $1.39[0.43$ to 4.48$] ; P=0.720$ & - \\
\hline Poor tolerance, n (\%) & $3 / 43(7 \%)$ & $9 / 48(19 \%)$ & $2.08[1.00$ to 4.30$] ; P=0.049$ & $1.97[0.89$ to 4.30$] ; P=0.09$ \\
\hline
\end{tabular}

Values are given as mean ( \pm standard deviation) or proportion (\%).

AHRF, Acute Hypoxemic Respiratory Failure; ARDS, Acute Respiratory Distress Syndrome; Cl, 95\% Confidence Interval HR; Hazard Ratio (aHR, adjusted HR); NIV, Non-Invasive Ventilation; PEEP, Positive End-Expiratory Pressure; PS, Pressure Support; SAPS II, Simplified Acute Physiology Score; VT, Tidal Volume.

therefore taking into account the potential complications of intubation in patients who failed NIV within the first 24 hours.

Time to intubation and impact on outcome

It has been suggested that NIV failure in patients with AHRF is independently associated with poor outcome as compared to patients intubated without prior NIV [6]. Therefore, it is essential to assess intubation rates and the impact of NIV failure on outcome in different subsets of the population with AHRF. It was recently suggested at an international conference that NIV may be a first line treatment in mild ARDS [21]. Our study supports this contention, as the intubation rate in patients with mild ARDS did not differ from that recorded in non-ARDS patients. In our patients with moderate or severe ARDS, however, the intubation rate was much higher (68\%). Nevertheless, the mortality rate of patients failing NIV did not differ according to the time to intubation, in contrast with previous studies of patients with community acquired pneumonia [22] or receiving NIV during the post-extubation period [23]. We were unable to identify a time beyond which maintaining NIV may worsen outcome, and we believe that intubation should be decided according to standard criteria regardless of NIV duration. 
It could also be argued that in our study NIV was used in moderately ill patients, while more severe patients would have been intubated without prior NIV. However, the rate of severe ARDS $(19 / 82,23 \%)$ in our population is close to that reported in the recent Berlin definition [19]. Mortality rates observed in intubated patients with ARDS are usually higher in observational studies than in randomized controlled studies and can reach $45 \%$ in unselected cohorts of patients [24,25]. Thus, our mortality rate of $48 \%$ in ARDS patients who failed NIV and required intubation is in line with these cohort studies of intubated patients.

\section{Predictive factors for NIV failure}

As previously reported [6], immunosuppression had no influence on the success or failure of NIV; however, all eight patients in the subgroup having active or metastatic cancer failed NIV, and this factor remained significantly associated with NIV failure after adjustment (Table 2); thus, using NIV in this subgroup should be carefully considered. Not surprisingly, a low GCS and, to a lesser extent, shock were associated with NIV failure. Although neither controlled studies $[17,18]$ nor surveys $[5,7]$ found that the occurrence of shock was a risk factor of intubation, two others studies found that shock was associated with NIV failure $[8,22]$.

Several studies found that hypoxemia was independently associated with NIV failure [7-9,22]. Our results confirm that stratification of patients according to the clinical severity of ARDS using the recent Berlin definition was clearly associated with the risk of NIV failure, with a low risk in patients with mild ARDS, increasing to $84 \%$ in those who had a $\mathrm{PaO}_{2} / \mathrm{FiO}_{2} \leq 100 \mathrm{mmHg}$ at initiation of NIV. However, a cut-off of $150 \mathrm{mmHg}$ (a value close to that reported by Antonelli et al. [9]) appeared to more accurately segregate patients who failed from those who succeeded NIV. Therefore, whereas almost all patients with severe ARDS are likely to fail NIV, some patients with "moderate" ARDS might still benefit from a NIV trial.

\section{Limitations}

Our study was conducted in a single unit with a longstanding experience in the practice of NIV and, therefore, our results may not be applicable to other centers with less extensive experience. Experience and nursedriven protocols may improve NIV tolerance, and we report a poor tolerance rate of only $13 \%$ after one hour of NIV. In line with previous studies [5], poor tolerance was associated with NIV failure in univariate analysis but not after adjustment for other variables associated with NIV failure. However, whereas rate of NIV failure could be significantly reduced for hypercapnic patients in experienced centers [26], our rate of intubation was not lower in this series than in surveys including less experienced centers [5,7]. Another limitation is the retrospective nature of the study. However, prospective data collection of ventilatory parameters under NIV was available for a vast majority of our patients and, because of the availability of computerized medical charts for all patients, all those receiving NIV for AHRF could be analyzed.

\section{Conclusion}

The major implications of our results are to easily identify hypoxemic patients who may benefit from NIV. Intubation rates did not exceed 35\% in non-ARDS and mild ARDS and NIV may thus be used as the first-line ventilatory support, as recently suggested [21]. By contrast, $84 \%$ of severe ARDS required intubation and NIV does not appear beneficial in this subset of patients; however, the time to intubation after NIV failure did not seem to influence outcome of patients. In patients with moderate ARDS, NIV may be worth attempting in those having a $\mathrm{PaO}_{2} / \mathrm{FiO}_{2}$ ratio $>150$ in the absence of hemodynamic instability or altered consciousness; further studies are needed to define the most appropriate use of NIV in these patients.

\section{Key messages}

- Intubation rates significantly differed between ARDS and non-ARDS patients and according to clinical severity of ARDS: $31 \%$ in mild, $62 \%$ in moderate and $84 \%$ in severe ARDS.

- NIV may be used as the first-line ventilatory support in mild ARDS whereas it does not appear beneficial in severe ARDS.

- In patients with moderate ARDS, NIV may be worth attempting in those having a $\mathrm{PaO} 2 / \mathrm{FiO} 2$ ratio $>150$.

- The time to intubation after NIV failure did not seem to influence outcome of patients.

- Active cancer, shock, moderate/severe ARDS, lower Glasgow coma score and lower positive endexpiratory pressure level at NIV initiation were predictors of NIV failure.

\section{Abbreviations}

AHRF: Acute Hypoxemic Respiratory Failure; ARDS: Acute Respiratory Distress Syndrome; GCS: Glasgow Coma Scale; ICU: Intensive Care Unit; NIV: NonInvasive Ventilation; PEEP: Positive End-Expiratory Pressure; RASS: Richmond Agitation-Sedation Scale; SAPS: Sequential Organ Failure Assessment.

\section{Competing interests}

The authors declare that they have no competing interests.

\section{Authors' contributions}

$A W T, C B B$ and $D C$ were responsible for study concept and design. DC, CF, $\mathrm{ACl}$ and $\mathrm{FB}$ were responsible for acquisition of the data. AWT, DC, CF, ACl, FB and $\mathrm{CBB}$ were responsible for the analysis and interpretation of the data. $A W T$ and $C B B$ drafted the manuscript:: $A W T, D C, C F, A C l, F B$ and $C B B$ were responsible for critical revision of the manuscript for important intellectual 
content. CBB and AWT performed the statistical analysis. CBB and AWT supervised the study. All authors read and approved the final manuscript.

\section{Acknowledgments}

Some of the results of this study have been previously reported in the form of an abstract at the 2013 meeting of the American Thoracic Society in Philadelphia, PA, USA.

\section{Author details}

${ }^{1}$ Medical Intensive Care Unit, AP-HP, Henri Mondor University Hospital, Créteil, France. ${ }^{2}$ Réanimation Médicale, CHU de Poitiers, 2 rue de la Milétrie, 86021, Poitiers, France. ${ }^{3}$ INSERM U955, Créteil, France.

Received: 19 July 2013 Accepted: 24 October 2013

Published: 11 November 2013

\section{References}

1. Brochard L, Mancebo J, Wysocki M, Lofaso F, Conti G, Rauss A, Simonneau G, Benito S, Gasparetto A, Lemaire F, et al: Noninvasive ventilation for acute exacerbations of chronic obstructive pulmonary disease. $N$ Engl J Med 1995, 333:817-822.

2. Lightowler JV, Wedzicha JA, Elliott MW, Ram FS: Non-invasive positive pressure ventilation to treat respiratory failure resulting from exacerbations of chronic obstructive pulmonary disease: Cochrane systematic review and meta-analysis. BMJ 2003, 326:185.

3. Keenan SP, Sinuff T, Cook DJ, Hill NS: Which patients with acute exacerbation of chronic obstructive pulmonary disease benefit from noninvasive positive-pressure ventilation? A systematic review of the literature. Ann Intern Med 2003, 138:861-870.

4. Masip J, Roque M, Sanchez B, Fernandez R, Subirana M, Exposito JA: Noninvasive ventilation in acute cardiogenic pulmonary edema: systematic review and meta-analysis. JAMA 2005, 294:3124-3130.

5. Demoule A, Girou E, Richard JC, Taille S, Brochard L: Increased use of noninvasive ventilation in French intensive care units. Intensive Care Med 2006, 32:1747-1755.

6. Demoule A, Girou E, Richard JC, Taille S, Brochard L: Benefits and risks of success or failure of noninvasive ventilation. Intensive Care Med 2006, 32:1756-1765

7. Schettino G, Altobelli N, Kacmarek RM: Noninvasive positive-pressure ventilation in acute respiratory failure outside clinical trials: experience at the Massachusetts General Hospital. Crit Care Med 2008, 36:441-447.

8. Rana S, Jenad H, Gay PC, Buck CF, Hubmayr RD, Gajic O: Failure of non-invasive ventilation in patients with acute lung injury: observational cohort study. Crit Care 2006, 10:R79.

9. Antonelli M, Conti G, Esquinas A, Montini L, Maggiore SM, Bello G, Rocco M, Maviglia R, Pennisi MA, Gonzalez-Diaz G, Meduri GU: A multiple-center survey on the use in clinical practice of noninvasive ventilation as a first-line intervention for acute respiratory distress syndrome. Crit Care Med 2007, 35:18-25.

10. Agarwal R, Aggarwal A, Gupta D: Role of noninvasive ventilation in acute lung injury/acute respiratory distress syndrome: a proportion meta-analysis. Respir Care 2010, 55:1653-1660.

11. Hilbert G, Gruson D, Vargas F, Valentino R, Gbikpi-Benissan G, Dupon M, Reiffers J, Cardinaud JP: Noninvasive ventilation in immunosuppressed patients with pulmonary infiltrates, fever, and acute respiratory failure. N Engl J Med 2001, 344:481-487.

12. Antonelli M, Conti G, Bufi M, Costa MG, Lappa A, Rocco M, Gasparetto A, Meduri GU: Noninvasive ventilation for treatment of acute respiratory failure in patients undergoing solid organ transplantation: a randomized trial. JAMA 2000, 283:235-241.

13. Auriant I, Jallot A, Herve P, Cerrina J, Le Roy LF, Fournier JL, Lescot B, Parquin F: Noninvasive ventilation reduces mortality in acute respiratory failure following lung resection. Am J Respir Crit Care Med 2001, 164:1231-1235.

14. Squadrone V, Coha M, Cerutti E, Schellino MM, Biolino P, Occella P, Belloni G, Vilianis G, Fiore G, Cavallo F, Ranieri VM, Piedmont Intensive Care Units Network (PICUN): Continuous positive airway pressure for treatment of postoperative hypoxemia: a randomized controlled trial. JAMA 2005, 293:589-595.

15. Confalonieri M, Potena A, Carbone G, Porta RD, Tolley EA, Umberto Meduri $G$ : Acute respiratory failure in patients with severe community-acquired pneumonia. A prospective randomized evaluation of noninvasive ventilation. Am J Respir Crit Care Med 1999, 160:1585-1591.

16. Martin TJ, Hovis JD, Costantino JP, Bierman MI, Donahoe MP, Rogers RM, Kreit JW, Sciurba FC, Stiller RA, Sanders MH: A randomized, prospective evaluation of noninvasive ventilation for acute respiratory failure. Am J Respir Crit Care Med 2000, 161:807-813.

17. Delclaux C, L'Her E, Alberti C, Mancebo J, Abroug F, Conti G, Guerin C, Schortgen F, Lefort $Y$, Antonelli $M$, Lepage $E$, Lemaire F, Brochard L: Treatment of acute hypoxemic nonhypercapnic respiratory insufficiency with continuous positive airway pressure delivered by a face mask: A randomized controlled trial. JAMA 2000, 284:2352-2360.

18. Ferrer M, Esquinas A, Leon M, Gonzalez G, Alarcon A, Torres A: Noninvasive ventilation in severe hypoxemic respiratory failure: a randomized clinical trial. Am J Respir Crit Care Med 2003, 168:1438-1444.

19. The ARDS Definition Task Force: Acute Respiratory Distress Syndrome: the Berlin Definition. JAMA 2012, 307:2526-2533.

20. Ely EW, Truman B, Shintani A, Thomason JW, Wheeler AP, Gordon S, Francis J, Speroff T, Gautam S, Margolin R, Sessler CN, Dittus RS, Bernard GR: Monitoring sedation status over time in ICU patients: reliability and validity of the Richmond Agitation-Sedation Scale (RASS). JAMA 2003, 289:2983-2991.

21. Ferguson N, Fan E, Camporota L, Antonelli M, Anzueto A, Beale R, Brochard L, Brower R, Esteban A, Gattinoni L, Rhodes A, Slutsky AS, Vincent JL, Rubenfeld GD, Thompson BT, Ranieri VM: The Berlin definition of ARDS: an expanded rationale, justification, and supplementary material. Intensive Care Med 2012, 38:1573-1582. Erratum in: Intensive Care Med 2012, 38:1731-1732.

22. Carrillo A, Gonzalez-Diaz G, Ferrer M, Martinez-Quintana ME, Lopez-Martinez A, Llamas N, Alcazar M, Torres A: Non-invasive ventilation in communityacquired pneumonia and severe acute respiratory failure. Intensive Care Med 2012, 38:458-466

23. Esteban A, Frutos-Vivar F, Ferguson ND, Arabi Y, Apezteguia C, Gonzalez M, Epstein SK, Hill NS, Nava S, Soares MA, D'Empaire G, Alía I, Anzueto A: Noninvasive positive-pressure ventilation for respiratory failure after extubation. N Engl J Med 2004, 350:2452-2460.

24. Brun-Buisson C, Minelli C, Bertolini G, Brazzi L, Pimentel J, Lewandowski K, Bion J, Romand JA, Villar J, Thorsteinsson A, Damas P, Armaganidis A, Lemaire F, ALIVE Study Group: Epidemiology and outcome of acute lung injury in European intensive care units. Results from the ALIVE study. Intensive Care Med 2004, 30:51-61.

25. Phua J, Badia JR, Adhikari NK, Friedrich JO, Fowler RA, Singh JM, Scales DC, Stather DR, Li A, Jones A, Gattas DJ, Hallett D, Tomlinson G, Stewart TE, Ferguson ND: Has mortality from acute respiratory distress syndrome decreased over time? A systematic review. Am J Respir Crit Care Med 2009, 179:220-227.

26. Contou D, Fragnoli C, Cordoba-Izquierdo A, Boissier F, Brun-Buisson C, Thille AW: Noninvasive ventilation for acute hypercapnic respiratory failure: intubation rate in an experienced unit. Respir Care 2013, 58:2045-2052.

doi:10.1186/cc13103

Cite this article as: Thille et al:: Non-invasive ventilation for acute hypoxemic respiratory failure: intubation rate and risk factors. Critical Care 2013 17:R269.

\section{Submit your next manuscript to BioMed Central and take full advantage of:}

- Convenient online submission

- Thorough peer review

- No space constraints or color figure charges

- Immediate publication on acceptance

- Inclusion in PubMed, CAS, Scopus and Google Scholar

- Research which is freely available for redistribution 